\title{
No increase in renal iodine excretion during pregnancy: a telling comparison between pregnant women and their spouses
}

\author{
Eftychia Koukkou, ${ }^{1}$ Stavros Kravaritis, ${ }^{2}$ Irene Mamali, ${ }^{3}$ Georgios G. Markantes, ${ }^{2}$ \\ Marina Michalaki, ${ }^{3}$ Georgios G. Adonakis, ${ }^{2}$ Neoklis A. Georgopoulos, ${ }^{2,3}$ \\ Kostas B. Markou ${ }^{3}$ \\ ${ }^{1}$ Department of Endocrinology, "Elena Venizelou" Hospital, Athens; ${ }^{2}$ Department of Obstetrics and Gynecology, \\ ${ }^{3}$ Department of Endocrinology, University of Patras; Greece
}

\begin{abstract}
OBJECTIVE: Adequate dietary iodine intake is necessary for normal thyroid gland function at all times, and most particularly during pregnancy. Increased iodine loss is cited, among other factors, as responsible for the increased iodine demand in this period. Our aim was to compare renal iodine excretion between women during all three pregnancy trimesters with that of their spouses and thereby to estimate the iodine intake in an a large sample of pregnant women in urban areas in Greece. DESIGN: Four hundred twenty-four healthy pregnant women were included prospectively (residents of Athens $n=218$, residents of Patras $n=206$ ). The spouses of 177 of these women following the same diet were also studied. Determinations included serum FT4, TSH and aTPO and urinary iodine excretion (UIE). RESULTS: No difference was found either in median UIE throughout pregnancy or between the UIE of the pregnant women and their spouses during the trimesters. Throughout pregnancy, mild iodine deficiency was noted and was classified as mild in $60 \%$, moderate in $30 \%$ and severe in $10 \%$ of the women studied. Users of iodized salt had significantly higher median UIE compared with non-users. Serum FT4 levels decreased and TSH increased as pregnancy progressed. CONCLUSIONS: Our study indicates that renal iodine excretion is not increased during pregnancy. This finding needs to be confirmed by further investigation in other populations with different iodine intakes. Thus, increased iodine requirements in pregnancy are possibly due to extra-renal causes. The population of pregnant women in Greek urban areas is mildly-and often moderately and severely-iodopenic and needs to be treated accordingly.
\end{abstract}

Key words: Iodine, Iodine deficiency, Pregnancy, Thyroid, Urinary iodine excretion

Address for correspondence:

Eftychia G. Koukkou, Department of Endocrinology, Diabetes and Metabolism "Elena Venizelou" Hospital, Athens, Greece, Tel.: +302106402389, Fax: +302106411156, E-mail:ekoukkou@gmail.com

Received 08-10-2013, Accepted 19-03-2014

\section{INTRODUCTION}

Iodine is an essential component of the hormones synthesized by the thyroid gland. Inadequate dietary iodine intake in pregnancy can lead to goiter and ab- 
normal development of the fetal nervous system and can have long-term adverse effects on the offspring's cognitive function, which might not be ameliorated by iodine sufficiency during childhood..$^{1-4}$ The frequency of todine deficiency disorders (IDD) is minimal in Western European and in many Central and Eastern European countries. ${ }^{5,6}$ However, partially inadequate dietary iodine intake is present in Europe, as well as in the USA, in pregnant and breastfeeding women, ${ }^{7-13}$ who have increased daily requirements. WHO recommends a minimum UIE of $150 \mathrm{mcg} / \mathrm{L}$ for pregnant and breastfeeding women as a marker of adequate dietary intake, ${ }^{7}$ whereas for the general population the lower normal limit is set at $100 \mathrm{mcg} / \mathrm{L}$. $^{7}$

The renal iodine clearance results chiefly from glomerular filtration, with no evidence for tubular secretion or active transport. It is generally accepted that glomerular filtration and hence renal excretion of iodine increases from the first weeks of pregnancy, resulting in a constant iodine "loss". ${ }^{14}$ In iodine sufficient environments, where thyroid iodine stores in the body are full, this loss may result in creating an inadequate substrate for thyroid hormone production, without causing any dysfunction. However, in iodine non-sufficient/deficient environments, the normal adaptation mechanisms are ineffective, resulting in increased TSH and decreased FT4 concentrations and in goiter development. ${ }^{15}$

In Greece, the study and management strategies of iodine deficiency were initiated 40 years ago, when iodopenic goiter was endemic. Over the years, a gradual amelioration of this adverse situation was noted mostly due to the increased use of iodized salt as well as to an overall improvement in quality of life. At the beginning of the 1980's, median UIE in Athens was $94 \mathrm{mcg} / \mathrm{L}$, which corresponds, according to the WHO criteria, to mild iodine deficiency ${ }^{16}$ After 2000, several studies were conducted in various regions of the country. In Southwestern Greece, median UIE was found to be $114 \mathrm{mcg} / \mathrm{L}$, corresponding to marginally adequate daily iodine intake. ${ }^{17}$ Another study conducted in Epirus, Northwestern Greece, which is one of the poorer European Union mountainous region, showed that the population studied was mildly iodine deficient ${ }^{18}$ as compared to people living in Athens whose median UIE was $310 \mathrm{mcg} / \mathrm{L}$ and the prevalence of goiter $4 \%$, denoting iodine sufficiency. ${ }^{18}$ However, not much data exist with respect to the sensitive population of pregnant women. In a recent preliminary study of our team in a small number of pregnant women in the greater Athens area, during the first trimester of their pregnancies, median UIE was $<100 \mathrm{mcg} / \mathrm{L}$ in more than $50 \%$ of the cases. Furthermore, $1 / 3$ of them had median UIE $<50 \mathrm{mcg} / \mathrm{L}$. These values indicate mild and moderate iodine deficiency respectively. ${ }^{19}$

In the present study, UIE was measured in pregnant women throughout all three pregnancy trimesters in two big cities, Athens and Patras, and compared to that of their spouses on the same diet. Our primary goal was to compare renal iodine excretion between the two teams, that is wives vs. husbands, and our secondary objective was to estimate UIE in a large sample of pregnant women living in urban Greek areas.

\section{MATERIALS AND METHODS}

The study was conducted in two hospitals: the "Elena Venizelou" Maternity Hospital in Athens and the University Hospital of Patras. Four hundred and twenty-four healthy, pregnant women with a mean age of 30 years were included in the study, irrespective of the pregnancy trimester (Athens $n=218$, Patras $n=206)$. Some of them $(n=126)$ were studied during more than one trimester. Two hundred and twelve observations in the $1^{\text {st }}$ trimester, 131 in the 2nd and 152 in the 3 rd were collected. One hundred and seventy-seven of the women (Group 1) were compared with their healthy spouses on the same diet (Group 2), regardless of the pregnancy trimester. All participants were euthyroid without a past history of thyroid disease. None was taking iodine containing preparations. All women completed a special questionnaire documenting anthropometric (age, body weight, height) and obstetric data (week of gestation) (Table 1), and a subset of them furnished

Table 1. Characteristics of total pregnant women. Values are expressed as mean $\pm \mathrm{SD}$

\begin{tabular}{lcccc}
\hline & Number & $\begin{array}{c}\text { Age } \\
\text { (years) }\end{array}$ & $\begin{array}{c}\text { Weight } \\
(\mathbf{k g})\end{array}$ & $\begin{array}{c}\text { Week of } \\
\text { gestation }\end{array}$ \\
\hline 1st trimester & 212 & $30.3 \pm 7.8$ & $65.4 \pm 10.4$ & $9.8 \pm 2.4$ \\
2nd trimester & 131 & $30.2 \pm 10.6$ & $71.3 \pm 14.1$ & $21.7 \pm 3.6$ \\
3rd trimester & 152 & $30.7 \pm 9.3$ & $77.7 \pm 13.9$ & $33.7 \pm 4.7$ \\
\hline
\end{tabular}


data regarding the use of iodized salt. All subjects provided informed consent.

UIE was measured twice in a spot sample collected on two different days and the mean value was used. Blood samples were centrifuged and the sera were frozen at $-20^{\circ} \mathrm{C}$ until hormonal determinations were performed, which was carried out at the Hormonal Laboratory of the University Hospital of Patras. Serum FT4, TSH and aTPO were determined by electrochemiluminescence (Elecsys 2010, Roche Diagnostics) and urine iodine excretion (UIE) by a photometric method (Sandell-Kolthoff reaction). ${ }^{20}$ Our laboratory is taking part in an external evaluation program for urinary iodine excretion determination conducted by the EQUIP Program (Atlanta, USA). The study was approved by both hospitals' Ethics Committees.

\section{Statistics}

All statistical procedures were performed using SPSS for Windows, version 9.0.1 (Chicago, Illinois, 6061 USA). The normality of UIE, TSH, FT4 and $\mathrm{Tg}$ distributions were checked by the One-Sample Kolmogorov-Smirnov test. Differences among the three trimesters for the UIE, TSH, FT4 and Tg were evaluated by the independent-samples Kruskal-Wallis test. When the p-value from the abovementioned test statistics was significant, the Mann-Whitney U test was performed to determine the groups that differed from each other. Comparisons between Groups 1 and 2 were performed by the Mann-Whitney U test. A $P$ value less of than 0.05 was considered significant.

\section{RESULTS}

The median UIE of the 177 women (Group 1) as a whole was $135.9(20-628.1 \mathrm{mcg} / \mathrm{L})$, similar to the median UIE of their spouses (Group 2) 138.4 (range $20.9-560.4 \mathrm{mcg} / \mathrm{L}$ ), the latter categorizing them (Group 2) as iodine sufficient according to the WHO. Interestingly, comparison of Group 1 vs Group 2 revealed no significant difference between UIE in any pregnancy trimester (Table 2).

After dividing Group 2 (men) into those with less than optimal (UIE $<150 \mathrm{mcg} / \mathrm{L}$ ), optimal (UIE $150-250 \mathrm{mcg} / \mathrm{L}$ ) and excess (UIE $>250 \mathrm{mcg} / \mathrm{L}$ ) iodine intake according to the WHO criteria, no significant difference between the UIE of pregnant women and their paired spouses in any pregnancy trimester was found in the optimal UIE group (Table 3a).

In the less than optimal group according the men's UIE, the pregnant women had significantly higher UIE compared to their spouses, while exactly the opposite was found in the iodine excess group (Table $3 \mathrm{~b}$ and Table 3c).

Thyroid hormones exhibited the expected changes with the progression of pregnancy. Specifically, from

Table 3a. UIE in pregnant women and their spouses in the three trimesters in the optimal UIE group $(150-250 \mathrm{mcg} / \mathrm{L})$. Values are expressed as mean $\pm \mathrm{SD}$

\begin{tabular}{lccc}
\hline & $\begin{array}{c}\mathbf{1}^{\text {st }} \text { trimester } \\
(\mathbf{n = 1 7})\end{array}$ & $\begin{array}{c}\mathbf{2}^{\text {nd }} \text { trimester } \\
(\mathbf{n = 1 3})\end{array}$ & $\begin{array}{c}\mathbf{3}^{\text {rd }} \text { trimester } \\
(\mathbf{n = 2 4})\end{array}$ \\
\hline $\begin{array}{l}\text { Pregnant women } \\
\text { UIE (mcg/L) }\end{array}$ & $179.1 \pm 94.4$ & $163.7 \pm 87.3$ & $172.8 \pm 83.5$ \\
Spouses & $188.1 \pm 30.3$ & $182.9 \pm 21.2$ & $190.1 \pm 21.1$ \\
UIE (mcg/L) & & & \\
p & 0.138 & 0.694 & 0.591 \\
\hline
\end{tabular}

TABLE 3b. UIE in pregnant women and their spouses in the three trimesters in the suboptimal UIE group $(<150 \mathrm{mcg} / \mathrm{L})$. Values are expressed as mean $\pm \mathrm{SD}$

\begin{tabular}{lccc}
\hline & $\begin{array}{c}\mathbf{1}^{\text {st }} \text { trimester } \\
(\mathbf{n = 3 5})\end{array}$ & $\begin{array}{c}\mathbf{2}^{\text {nd }} \text { trimester } \\
(\mathbf{n = 1 5})\end{array}$ & $\begin{array}{c}\mathbf{3}^{\text {rd }} \text { trimester } \\
(\mathbf{n}=\mathbf{2 6})\end{array}$ \\
\hline $\begin{array}{l}\text { Pregnant women } \\
\text { UIE }(\mathrm{mcg} / \mathrm{L})\end{array}$ & $145.8 \pm 77.7$ & $155.8 \pm 67.9$ & $134.5 \pm 72$ \\
Spouses & $92.6 \pm 36.7$ & $101.2 \pm 27$ & $108.1 \pm 30.9$ \\
UIE $(\mathrm{mcg} / \mathrm{L})$ & & & \\
$\mathrm{p}$ & 0.001 & 0.001 & 0.009 \\
\hline
\end{tabular}

Table 2. UIE in pregnant women and their spouses in each trimester. Values are depicted as median (minimum-maximum)

\begin{tabular}{lccc}
\hline & $\mathbf{1}^{\text {st }}$ trimester $(\mathbf{n}=\mathbf{5 7})$ & $\mathbf{2}^{\text {nd }}$ trimester $(\mathbf{n}=\mathbf{4 6})$ & $\mathbf{3}^{\text {rd }}$ trimester $(\mathbf{n}=\mathbf{7 4})$ \\
\hline Pregnant women & $144.1(30.1-628.1)$ & $135.5(23.1-540.4)$ & $131.0(20-431.5)$ \\
Spouses & $135.7(22.9-560.4)$ & $128.8(47.1-469.7)$ & $143.6(20.9-459.1)$ \\
p & 0.207 & 0.620 & 0.309 \\
\hline
\end{tabular}


TABLE 3c. UIE in pregnant women and their spouses in the three trimesters in the iodine excess group ( $>250 \mathrm{mcg} / \mathrm{L})$. Values are expressed as mean $\pm \mathrm{SD}$

\begin{tabular}{lccc}
\hline & $\begin{array}{c}\mathbf{1}^{\text {st }} \text { trimester } \\
(\mathbf{n = 9})\end{array}$ & $\begin{array}{c}\mathbf{2}^{\text {nd }} \text { trimester } \\
(\mathbf{n = 7})\end{array}$ & $\begin{array}{c}\mathbf{3}^{\text {rd }} \text { trimester } \\
(\mathbf{n = 9})\end{array}$ \\
\hline $\begin{array}{l}\text { Pregnant women } \\
\text { UIE }(\mathrm{mcg} / \mathrm{L})\end{array}$ & $165.9 \pm 59.7$ & $208.3 \pm 92.6$ & $193.3 \pm 128$ \\
$\begin{array}{l}\text { Spouses } \\
\text { UIE }(\mathrm{mcg} / \mathrm{L})\end{array}$ & $338.8 \pm 112.6$ & $317.6 \pm 102$ & $313.5 \pm 60.4$ \\
$\mathrm{p}$ & 0.001 & 0.05 & 0.02 \\
\hline
\end{tabular}

the first to the third trimester, FT4 decreased and TSH increased significantly, but both remained within the normal limits. The percentage of increased autoantibodies (aTPO) slightly declined with the progression of pregnancy $(\mathrm{p}=0.324)$. Serum Tg significantly increased at third trimester. Median UIE of pregnant women in any pregnancy trimester revealed no significant difference. The mean values of thyroid function tests and median values of UIE for all pregnant women studied are depicted in Table 4.

Mild iodine deficiency was noted in all trimesters of pregnancy, this finding applying to women from both cities studied (Athens: median UIE $=123 /$ range $=$ $21-620 \mathrm{mcg} / \mathrm{L}$, Patras: median UIE $=136 /$ range $=$ $<20-628 \mathrm{mcg} / \mathrm{L}, 0.21)$. Iodine deficiency was present through all pregnancy trimesters in a significant proportion of the subjects studied (Table 5). Users of iodized salt had statistically significantly higher UIE compared with non-users (medianL (range): users $(\mathrm{n}=108) 145 \mathrm{mcg} / \mathrm{L}(<20-628)$, non-users $(\mathrm{n}=68)$ $117 \mathrm{mcg} / \mathrm{L}(23-31), \mathrm{p}<0.05$.

\section{DISCUSSION}

The major advantage of this study is the concurrent estimate of UIE in pregnant women and their
Table 5. Percentage of women with suboptimal UIE in the three trimesters of pregnancy

\begin{tabular}{lccc}
\hline UIE (mcg/L) & $\begin{array}{c}\mathbf{1}^{\text {st }} \text { trimester } \\
(\mathbf{n = 2 1 2})\end{array}$ & $\begin{array}{c}\mathbf{2}^{\text {nd }} \text { trimester } \\
(\mathbf{n = 1 3 1})\end{array}$ & $\begin{array}{c}\mathbf{3}^{\text {rd }} \text { trimester } \\
(\mathbf{n = 1 5 2})\end{array}$ \\
\hline$<150$ & $57 \%$ & $65 \%$ & $60 \%$ \\
$<100$ & $32 \%$ & $35 \%$ & $28 \%$ \\
$<50$ & $8 \%$ & $10 \%$ & $7 \%$ \\
\hline
\end{tabular}

husbands both following the exact same diet. We observed no difference in urinary iodine excretion between pregnant women and their spouses as a whole, as well as when calculated according to pregnancy trimester. Mild iodine deficiency-estimated by determination of the median value for UIE-was noted in women from both cities, with a significant percentage presenting moderate or even severe iodine deficiency ( $30 \%$ and $10 \%$, respectively).

The presumed increase in renal iodine excretion during pregnancy dates back to the 1960's and has been quoted in various textbooks as "classical" knowledge since then. ${ }^{13,14}$ Old studies are scarce and difficult to evaluate in the present, while the classic techniques to evaluate glomerular filtration cannot be performed in pregnant women for obvious reasons. Thus, measuring renal iodine clearance is the only applicable technique. A specialized laboratory for plasma inorganic iodine determination is essential. The Hormonal Laboratory of the University Hospital of Patras possesses the technical knowhow to accurately measure UIE and is moreover participating in a relevant external evaluation program. However, simultaneous reliable plasma iodine concentration determination tends to be the international gold standard method and our laboratory is also working in order to establish this method, in line with its reference laboratory. To date, renal iodine loss in pregnancy can only be estimated

Table 4.

\begin{tabular}{lcccc}
\hline & $\mathbf{1}^{\text {st }}$ trimester $(\mathbf{n}=\mathbf{2 1 2})$ & $\mathbf{2}^{\text {nd }}$ trimester $(\mathbf{n}=\mathbf{1 3 1})$ & $\mathbf{3}^{\text {rd }}$ trimester $(\mathbf{n}=\mathbf{1 5 2})$ & $\mathbf{P}$ \\
\hline Median UIE $(\mathrm{mcg} / \mathrm{L})$ & $130($ range $21-628)$ & $125($ range $<20-<628)$ & $130($ range $<20-431)$ & 0.444 \\
Mean FT4 $(\mathrm{ng} / \mathrm{dl})$ & $1.218 \pm 0.38^{* \dagger}$ & $0.971 \pm 0.15 \ddagger$ & $0.927 \pm 0.14$ & $<0.01$ \\
Mean TSH $(\mathrm{mIU} / \mathrm{L})$ & $1.532 \pm 1.18 \dagger^{* *}$ & $1.667 \pm 0.93$ & $1.721 \pm 0.81$ & $<0.01$ \\
Median TG ng/ml & 13.92 (range $14-43)^{* *}$ & $12.44($ range $14-0.2) \ddagger$ & $31(45-18)$ & $<0.01$ \\
Increased anti $(\%)$ & 11 & 10 & 7 & 0.324 \\
\hline
\end{tabular}

${ }^{*} \mathrm{p}<0.01$ 1st vs 2 nd trimester; ${ }^{* *} \mathrm{p}<0.05$ 1st vs 3rd trimester; $\dagger \mathrm{p}<0.01$ 1st vs 3rd trimester; $\ddagger \mathrm{p}<0.01$ 2nd vs 3rd trimester. 
indirectly. Few studies have examined changes in UIE across pregnancy and those have produced varying results: some show increasing values across trimesters, some decreasing values and some no change, possibly based on the underlying iodine sufficiency of the populations studied. ${ }^{21-25}$ Our present study is the first to concurrently estimate UIE in pregnant women and their husbands following the exact same diet as them. Taking into account that dietary intake is the exclusive iodine source ${ }^{7}$ and that there was no difference in quality or quantity of daily food intake consumed by each couple (as documented by a special completed questionnaire), we assumed that UIE determination in both spouses would provide us with indirect information regarding the effect of pregnancy on renal iodine excretion. Our results showed that neither at the beginning of pregnancy nor with pregnancy progression is the renal iodine excretion of pregnant women increased, as the UIE presented no significant difference in each trimester and was no different from that of their husbands. If these results are accurate, to what should the increased iodine requirements of pregnancy be attributed? Apart from the urinary loss, another reason for increased iodine requirements in pregnancy is the $50 \%$ increase in thyroid hormone production, as noted above. Moreover, from the mid-second and during the third pregnancy trimesters, there is a constant iodine "output" from the mother to the fetus through the placenta, providing this essential compound to the fetal gland for thyroid hormone synthesis. Furthermore, it seems that the placenta is a sort of iodine store per se. ${ }^{26,27}$ Whether this iodine could have an embryo protective role under certain circumstances is still unknown.

When we examined the women's UIE by comparison with their spouse's iodine status, we found that there was no difference between their UIE and that of their spouses in the optimal UIE group, that is, UIE $150-250 \mathrm{mcg} / \mathrm{L}$. This supports our hypothesis, at least in the presence of adequate iodine intake, as this has also been previously reported ${ }^{21}$ However, in the lowest tritile of UIE excretion $(<150)$, women excreted less iodine throughtout pregnancy than their husbands, while in the highest tritile the contrary was found. These differences could be explained, as was suggested by Dworkin et al, by the existence of a urinary iodostat which is set according to iodine intake. ${ }^{21,28}$

Thyroid hormones presented the expected alterations: FT4 was found significantly higher in the $1^{\text {st }}$ in comparison to the $2^{\text {nd }}$ and 3 rd trimesters, while, although TSH was lower in the first in comparison to the third trimester, both remained within normal limits. These alterations are attributed to the major increase in hCG in early pregnancy, which exerts a partial TSH action due to its $\alpha$-subunit homology. ${ }^{29}$ $\mathrm{Tg}$ changes tend to represent normal fluctuations. Although the aTPO values tended to decrease with pregnancy progression, no significant difference in autoimmunity status was found, probably due to the relatively small sample size. It is accepted that pregnancy has a normal immunosuppressive effect and this also applies to thyroid autoimmunity. ${ }^{30}$

Greece is currently considered as an iodine sufficient country with only a few isolated areas of mild iodine deficiency. ${ }^{31}$ The results of the present study, in the small sample of husbands studied, confirm this observation. However, with respect to the population of pregnant women, at least those living in urban areas, However, mild iodine deficiency was present through all three pregnancy trimesters in our sample and was completely dependent on the level of iodized salt use. Recent studies in various countries have shown that even when UIE is within normal/acceptable limits, it is still lower than it was 20 years ago in the same populations. ${ }^{32}$ Nevertheless, a significant percentage of adult reproductive aged/pregnant women have a UIE at or below the levels of iodine sufficiency, ${ }^{33,34}$ as suggested by the International Organizations, and this is also true in school-aged children in areas with adequate UIE. ${ }^{33}$ A geographical variation regarding dietary iodine intake which is so pronounced that complementary iodine cannot eliminate it is plausible in these iodine-sufficient countries. ${ }^{9}$ Moreover, it is to be noted that even in countries such as the USA and the United Kingdom where adequate iodine intake has been established for a long period of time, or countries where food is iodized, iodine deficiency is documented in pregnant women and women of reproductive age. . $2,32,36,37^{-3}$

In conclusion, the results of the present study indirectly indicate that renal iodine excretion is not 
increased during pregnancy. This finding needs to be confirmed by further studies among other populations with different iodine intakes. The increased iodine requirements of gestation are possibly due to extra-renal causes. The majority of pregnant women in Greek urban areas are mildly iodopenic, with a non-negligible percentage presenting moderate and severe iodine deficiency, this underlining the need for identification of the disorder and appropriate treatment.

\section{FUNDING}

This study was partial supported by the Greek pharmaceutical company "Uni-Pharma".

\section{REFERENCES}

1. de Escobar GM, Obregón MJ, del Rey FE, 2007 Iodine deficiency and brain development in the first half of pregnancy. Public Health Nutr 10: 1554-1570.

2. Glinoer D, 2007 The importance of iodine nutrition during pregnancy. Public Health Nutr 10: 1542-1546.

3. Medeiros-Neto G, Camargo RY, Tomimori EK, 2012 Approach to and treatment of goiters. Med Clin North Am 96: 351-368.

4. Hynes KL, Otahal P, Hay I, Burgess GR, 2013 Mild iodine deficiency during pregnancy is associated with reduced educational outcomes in the offspring: 9-year follow-up of the gestational iodine cohort. J Clin Endocrinol Metab 98: 1954-1962.

5. Zimmermann MB, Andersson M, 2012 Update on iodine status worldwide. Curr Opin Endocrinol Diabetes Obes 19: 382-387.

6. ICCIDD Global Network. National Iodine Status in 2013. Available at http://www.iccidd.org. Accesesed August 2013.

7. Zimmermann MB, 2009 Iodine deficiency. Endocr Rev 30: 376-408.

8. Pearce EN, 2007 National trends in iodine nutrition: is everyone getting enough?. Thyroid 17: 823-827.

9. Nøhr SB, Laurberg P, Børlum KG, et al, 1993 Iodine deficiency in pregnancy in Denmark: Regional variations and frequency of individual iodine supplementation. Acta Obstet Gynecol Scand 72: 350-353.

10. Mian C, Vitaliano P, Pozza D, et al, 2009 Iodine status in pregnancy: role of dietary habits and geographical origin. Clin Endocrinol (Oxf) 70: 776-780.

11. Marchioni E, Fumarola A, Calvanese A, et al, 2008 Iodine deficiency in pregnant women residing in an area with adequate iodine intake. Nutrition 24: 458-461.

12. Kibirige MS, Hutchison S, Owen CJ, Delves HT, 2004 Prevalence of maternal dietary iodine insufficiency in the north east of England: implications for the fetus. Arch Dis Child Fetal Neonatal Ed 89: F436-439.

13. Koutras DA, Alexander WD 1964 Excretion of iodine. In: Koutras DA, Alexander WD (eds) Clinical Aspects of Iodine Metabolism, Blackwell Scientific Publications, Oxford, England; pp, 73-82.

14. Glinoer D, 2001 Pregnancy and Iodine. Thyroid 11: 471-481.

15. Doufas AG, Mastorakos G, Chatziioannou S, et al, 1999 The predominant form of non-toxic goiter in Greece is now autoimmune thyroiditis. Eur J Endocrinol 140: 505-511.

16. Michalaki M, Kyriazopoulou V, Paraskevopoulou P, Vagenakis AG, Markou KB, 2008 The odyssey of nontoxic nodular goiter (NTNG) in Greece under suppression therapy, and after improvement of iodine deficiency. Thyroid 18: 641-645.

17. Tsatsoulis A, Johnson EO, Andricula M, et al, 1999 Thyroid autoimmunity is associated with higher urinary iodine concentrations in an iodine-deficient area of Northwestern Greece. Thyroid 9: 279-283.

18. Kaloumenou I, Alevizaki M, Ladopoulos C, et al, 2007 Thyroid volume and echostructure in schoolchildren living in an iodine-replete area: relation to age, pubertal stage, and body mass index. Thyroid 17: 875-881.

19. Pearce EN, Alexiou M, Koukkou E, et al, 2012 Perchlorate and thiocyanate exposure and thyroid function in first-trimester pregnant women from Greece. Clin Endocrinol (Oxf) 77: 471-474.

20. Dunn JT, Crutchfield HE, Gutekunst R, Dunn AD, 1993 Two simple methods for measuring iodine in urine. Thyroid 3: 119-123.

21. Smyth PP, 1999 Variation in iodine handling during normal pregnancy. Thyroid 9: 637-642.

22. Stilwell G, Reynolds P, Parameswaran V, Blizzard L, Greenaway TM, Burgess JR, 2008 The Influence of Gestational Stage on Urinary Iodine Excretion in Pregnancy. J Clin Endocrinol Metab 93: 1737-1742.

23. Gültepe M, Ozcan O, Ipçioglu OM, 2005 Assessment of iodine intake in mildly iodine-deficient pregnant women by a new automated kinetic urinary iodine determination method. Clin Chem Lab Med 43: 280-284.

24. Brander L, Als C, Buess H, et al, 2003 Urinary iodine concentration during pregnancy in an area of unstable dietary iodine intake in Switzerland. J Endocrinol Invest 26: 389-396.

25. Koutras DA, 2000 Circulating iodide concentrations during and after pregnancy. J Clin Endocrinol Metab 85: 1345.

26. Smyth PP, Smith DF, Sheehan S, Higgins M, Burns R, O'Herlihy C, 2007 Short-term changes in maternal and neonatal urinary iodine excretion. Thyroid 17: 219-222.

27. Burns R, Azizi F, Hedayati M, Mirmiran P, O’Herlihy C, Smyth PP, 2011 Is placental iodine content related to dietary iodine intake? Clin Endocrinol (Oxf) 75: 261-264. 
28. Dworkin HJ, Jacquez JA, Beierwaltes WH, 1966 Relationship of iodine ingestion to iodine excretion in pregnancy. J Clin Endocrinol 26: 1329-1336.

29. Pierce JG, Faith MR, Giudice LC, Reeve JR, 1976. Structure and structure-function relationships in glycoprotein hormones. Ciba Found Symp 41: 225-250.

30. Smyth PP, Wijeyaratne CN, Kaluarachi WN, et al, 2005 Sequential studies on thyroid antibodies during pregnancy. Thyroid 15: 474-477.

31. Markou KB, Koukkou EG, 2012 The Greek population is iodine sufficient and not at risk of iodine-induced hyperthyroidism. J Nutr 142: 1611; author reply 1612.

32. Caldwell KL, Miller GA, Wang RY, Jain RB, Jones RL, 2008 Iodine status of the U.S. population, National Health and Nutrition Examination Survey 2003-2004. Thyroid 18: 1207-1214.

33. Caron P, Hoff M, Bazzi S, et al, 1997 Urinary iodine excretion during normal pregnancy in healthy women living in the southwest of France: correlation with maternal thyroid parameters. Thyroid 7: 749-754.

34. Hollowell JG, Staehling NW, Hannon WH, et al, 1998 Iodine nutrition in the United States. Trends and public health implications: iodine excretion data from National Health and Nutrition Examination Surveys I and III (1971-1974 and 1988-1994). J Clin Endocrinol Metab 83: 3401-3408.

35. Gowachirapant S, Winichagoon P, Wyss L, et al, 2009 Urinary iodine concentrations indicate iodine deficiency in pregnant Thai women but iodinesufficiency in their school-aged children. J Nutr 139: 1169-1172.

36. Hollowell JG, Haddow J, 2007 The prevalence of iodine deficiency in women of reproductive age in the United States of America. Public Health Nutr 10: 15321539.

37. Pearce EN, 2008 Iodine in pregnancy: is salt iodization enough? J Clin Endocrinol Metab 93: 2466-2468. 